\title{
CIDADÃOS E LATINOS NA \\ EXPERIÊNCIA JURIIDICA DA ROMA \\ ANTIGA: NOVAS POSSIBILIDADES PARA UM MODELO DE INCLUSÃO
}

\author{
CITIZENS AND LATINS IN THE LEGAL EXPERIENCE OF ANCIENT ROME: NEW POSSIBILITIES FOR \\ AN INCLUSION MODEL
}
CIUDADANOS Y LATINOS EN LA EXPERIENCIA JURÍDICA DE LA ROMA ANTIGUA: NUEVAS POSIBILIDADES PARA UN MODELO DE INCLUSIÓN

Luciene Dal Ri ${ }^{1}$

Arno Dal Ri Jr. ${ }^{2}$

RESUMO

\begin{abstract}
A cidadania e a latinidade sempre foram temas muito próximos quando se trata da Roma antiga. Observase que o status jurídico dos latinos era bastante diferenciado daquele dos demais não romanos. Devido ao seu particular status em relação ao sistema jurídico romano, as fontes e a doutrina sobre o tema evidenciam o não enquadramento dos latinos como peregrini. A particular relação desenvolvida entre romanos e latinos durante toda a existência de Roma teve bases culturais muito antigas, presentes na própria origem latina da cidade romana. O vínculo cultural e jurídico desenvolvido entre Roma e os demais latinos foi afetado por conta das guerras latinas, mas nunca foi apagado do sistema jurídico romano. A experiência romana de ius civitatis denota um diferente conceito de cidadania em relação àquela proposta pelo modelo do Estado-nação, abrindo possibilidades para uma concepção intermediária entre o cidadão e o estrangeiro.
\end{abstract}

PALAVRAS-CHAVES: Cidadãos. Latinos. Roma antiga.

ABSTRACT

The themes of Citizenship and Latinity have always been very closely linked when it comes to ancient Rome. It is observed that the legal status of Latins was very different from that of other non-Romans. Due to their special status in relation to the Roman legal system, sources and doctrines on the subject show the inadequacy of the Latins as peregrini. The special relationship developed between the Romans and Latins throughout the existence of Rome, had very old cultural bases, presented in the Latin origin of the Roman city. The cultural and legal link developed among Rome and other Latins was affected because of the Latin wars, but it was never completely removed from the Roman legal system. The Romans' experience of ius civitatis denotes a different concept of citizenship from that proposed by the model of Nation States, opening up possibilities for an intermediary concept between the citizen and the foreigner.

KEYWORDS: Citizens. Latins. Ancient Rome.

1 Doutora em Direito Civil-romanístico pela Università degli Studi di Roma - La Sapienza. Mestre em Estudos Medievais pela Pontificia Università Antonianum. Professora de História do Direito no curso de graduação em Direito e no programa de pós-graduação stricto sensu, Mestrado e Doutorado, em Ciência Jurídica na universidade do Vale do Itajaí (UNIVALI). Endereço: Rua Uruguai 458, Centro, Bloco 16, 88302-202 - Itajaí - SC. E-mail: luciene.dalri@univali.br

2 Doutor em Direito Internacional pela Universidade Luigi Bocconi de Milão, com pós-doutorado pela Université Paris I (Panthéon-Sorbonne). Mestre em Direito e Política da União Européia pela Universidade de Pádua. Professor de Teoria e História do Direito Internacional nos cursos de graduação e de pós-graduação stricto sensu em Direito na Universidade Federal de Santa Catarina (UFSC). Endereço: Campus Universitário Reitor João David Ferreira Lima - Trindade - Florianópolis - SC - 88040-970. E-mail: arno@ccj.ufsc.br 
La ciudadanía y la latinidad siempre fueron temas muy próximos cuando se trata de la Roma antigua. Se observa que el status jurídico de los latinos era bastante distinto del de los demás no romanos. Debido a su particular status en relación al sistema jurídico romano, las fuentes y la doctrina sobre el tema evidencian el no encuadramiento de los latinos como peregrini. La particular relación desarrollada entre romanos y latinos durante toda la existencia de Roma tenía bases culturales muy antiguas, presentes en el propio origen latino de la ciudad romana. El vínculo cultural y jurídico desarrollado entre Roma y los demás latinos se vio afectado por las guerras latinas, pero nunca fue borrado del sistema jurídico romano. La experiencia romana de ius civitatis denota un diferente concepto de ciudadanía en relación a aquella propuesta por el modelo de Estado-nación, abriendo posibilidades para una concepción intermedia entre el ciudadano y el extranjero.

PALABRAS CLAVE: Ciudadanos. Latinos. Roma antigua.

\section{CIDADÃOS E LATINOS NA EXPERIÊNCIA JURÍDICA DA ROMA ANTIGA}

\section{INTRODUÇÃO}

O status civitatis como situação do cidadão dentro do sistema jurídico romano foi um dos principais instrumentos jurídicos utilizados por Roma nas suas relações com o interior e com o exterior do povo romano, definindo quem é cidadão e, consequentemente, quem não é. Os não romanos são identificados como latinos ou como peregrinos, denotando diferença de enquadramento em relação ao sistema jurídico romano. O status de latino apresenta peculiaridades e prerrogativas não estendidas aos peregrinos em geral, como a possibilidade de voto nas assembleias romanas, uma vez fixado o domicílio em Roma. Tais prerrogativas suscitam o debate na doutrina sobre o enquadramento dos latinos como estrangeiros, no sentido de estranhos ou externos em relação à cultura romana ou como um status intermediário entre cidadãos e estrangeiros.

Para a abordagem do tema será utilizada a consulta às fontes romanas jurídicas e literárias. Dar-se-á, ainda, ênfase à terminologia utilizada, tomando em consideração o fértil debate da doutrina sobre o tema.

\section{ELEMENTOS DA CIDADANIA ROMANA}

A Roma antiga apresenta nos conceitos de Quiris e de civis, ligados intimamente à noção de status civitatis e de civitas - como elementos que vinculam a pessoa ao sistema jurídico -, delineamentos que conduzem a uma concepção de cidadania romana. Deste modo, portanto, o Quiris, e posteriormente o civis, seriam entendidos como partes do povo romano, unidos pelo mesmo ius, gozando de certos direitos e incumbidos de certos deveres. ${ }^{3}$

A concepção de civis deve ser trabalhada em conjunto com a concepção de civitas, visto a origem e a intrínseca ligação existente entre os termos. A civitas era inicialmente a qualidade

3 O conceito ius Quiritium será utilizado mesmo em fontes de idade imperial para indicar o direito de cidadania romana, e em particular aquele concedido aos latinos, enquanto no caso da concessão aos peregrinos o termo mais usado era de civitas romana. CATALANO, Pierangelo. Populus Romanus Quirites. Torino: Giappichelli, 1974, p. 146: «Ius Quiritium e civitas Romana sono espressioni, riferentisi allo status di "cittadino" romano, cioè di parte del populus Romanus Quirites, le quali hanno origini storiche diverse. La prima espressione è certamente più antica (come Quiris è anteriore a civis) e risponde a una concezione di populus più concreta, in cui prevale I“aspetto della pluralità dei Quirites; la seconda, pur sempre concepita come ius omnium risente in qualche modo del processo di astrazione subito da populus in connessione al decadere dell“importanza politica e sociale dei comitia». 
própria do cidadão, desenvolvendo posteriormente o significado de conjunto de cidadãos ${ }^{4}$. Fruto deste fenômeno, a construção da cidadania como instituto jurídico da Roma antiga não é delineada apenas como uma ligação entre partes da comunidade, formando-a, mas também é vinculada a um espaço geográfico de exercício de tais direitos. Será o território da cidade, o interior do pomerium, a dar concretude, materialidade, a este espaço de cidadania. ${ }^{5}$

Desde as primeiras fases do período arcaico ${ }^{6}$, um dos elementos de mais forte caracterização do civis romano encontra-se no fato de se pertencer ou não a uma gens romana. Consideradas organismos anteriores e constituidores da civitas, a gens e a família assumiam a condição de pressupostos políticos e sociais de Roma.

O pressuposto de liberdade e de vínculo com Roma, concretizado no fato de pertencer a uma gens, pode ser observado desde o período mais remoto da cidade. Este é transmitido por meio do nascimento, como delineia o jurista romano Gaio, na obra Institutiones. É muito claro na exposição de Gaio que o sistema jurídico romano era baseado no critério ius sanguinis para a concessão da cidadania, estendendo-a também por adoção, por manumissão (concessão da liberdade ao escravo) pelo verificar-se de certas condições e pela concessão individual ou coletiva.

As diferentes interpretações dadas às fontes e ao termo populus em relação às suas partes (os cidadãos) e à constituição romana, com as suas consequências, fazem com que o estudo do tema torne-se bastante complexo. As doutrinas alemãs e italianas, neste âmbito, forneceram contribuições fundamentais para o debate, apresentando contrastes e intersecções, em muito fruto de uma forte influência filosófica e política. ${ }^{7}$

Mesmo com tantas interpretações, a concepção do termo populus, em relação à sua origem filológica poplus-, encontra-se pacificada na doutrina, sendo considerada como "multidão", também relativa a um "insieme di armati".8 $\mathrm{O}$ tema, porém, ainda é fonte de inúmeras controvérsias doutrináriais, estas últimas surgidas em teorias que se delineiam a partir do século XIX.

A) Mommsen ${ }^{9}$ propõe a teoria de identificação entre populus e «Staat» como ente ideal e

4 Dentro de uma análise semântica, Crifò (Civis. La cittadinanza tra antico e moderno. Roma-Bari: Laterza, 2004 , p. 26 s.) teoriza que a passagem do significado de civitas como cidadão para o significado de conjunto de cidadãos e posteriormente cidade reflete a lógica de construção de Roma. A civitas romana é então concebida como uma organização social baseada na estrutura patriarcal-gentilícia religiosa, feita a partir do cidadão e para o cidadão. Ver CRIFÒ, Giuliano. Civis. La cittadinanza tra antico e moderno, p. 24.

5 A afirmação de Crifò (Civis. La cittadinanza tra antico e moderno, p. 28) sobre o vínculo entre o instituto de cidadadania e o território romano é contraposta à de Gaudemet (Les Institutions de I'Antiquité, 7. ed., Paris: Montchrestien, 2002, p. 180) "La citoyenneté dans la Rome classique n'implique aucune référence à une donnée territoriale". Cabe delinear, no confronto entre os dois autores, a ligação entre cidadania e território para o exercício de alguns direitos como o ius suffragii e a provocatio ad populum (até o início do II a.C.), pondera-se, porém, que concessão da cidadania romana não encontra limites em origem e território, podendo ser adquirida por qualquer homem. Ver a propósito da concepção espacial romana CATALANO, Pierangelo. Aspetti spaziali del sistema giuridico-religioso romano. Mundus, templum, urbs, ager, Latium, Italia. Aufstieg und Niedergang der Rômischen welt, II, Principat $16.1,1978$ p. 479 ss.

6 O período arcaido pode ser definido, segundo Orestano (Il problema delle persone giuridiche in diritto romano. Torino: Giappichelli, 1967, p. 40), como o período compreendido entre a data tradicional da fundação de Roma e a Lei das XII tábuas.

7 DAL RI. Luciene. Ius Fetiale. As origens do direito internacional no universalismo romano. Ijuí: Unijuí, 2011, p. 324 ss.

8 A origem indoeuropeia do termo é encontrada também junto aos Umbros através do termo poplo-, sobre a definição latina de poplus e aquela umbra de poplo-, teuta/tota-, ver: CATALANO, Pierangelo. Linee del sistema sovrannazionale romano. Torino: Giappichelli, 1965, p. 486, nt. 144a; CATALANO, Pierangelo. Populus Romanus Quirites, p. 108 e ss. especialmente p. 114, que indica DEVOTO, Giacomo. La città e lo stato degli Umbri. In: L'Umbria nella storia, nella letteratura, nell'arte. Bologna, 1954, p. 29 s. Diversamente, COLI, Ugo. Il diritto pubblico degli Umbri e le tavole Eugubine. Milano: Giuffrè,1958, p. 79 ss.; DE FRANCISCI, Pietro. Primordia Civitatis. Romae: Apollinaris, 1959, p. 736.

9 MOMMSEN, Theodor. Römische Staatsrecht III. Leipzig: Teubner, 1887, p. 04 ss.: «Populus ist der Staat, insofern er auf der nationalen Zusammengehörigkeit der Personen ruht, während er als örtlich unter einer Staatsgewalt begriffen das imperium, das Reich ist». O autor identifica também populus com civitas. A concepção de populus em Mommsen remonta ao RUBINO, Joseph. Über den Entwickelungsgang der römischen Verfassumg bis zum Höhepunkte der Republik. Cassel, 1839, p. 233. 
soberano, apresentando forte influência hegeliana. ${ }^{10} \mathrm{Em}$ paralelo à compreensão do populus como "Estado" atribui-se-Ihe um segundo significado, mais concreto, de «Volksversammlung», ou seja, de povo reunido em assembléia. ${ }^{11} \mathrm{~A}$ doutrina apresenta algumas variações em relação ao uso do termo "Estado", identificando-o também à res publica, civitas e outros, sem para tanto liberar-se da aplicação de conceitos modernos, ideais e abstratos.

B) Orestano, em uma relação de contraste e intersecção com a teoria proposta por Mommsen, critica o uso do conceito "Estado"; mas utiliza amplamente o termo "ordenamento", identificando-o com populus e res publica; e mantendo, por meio da sua concepção de imperium, a abstração do poder em relação ao cidadão e à reunião desses. ${ }^{12}$ Ele diferencia-se, porém, ao analisar o conceito de populus elaborado por juristas, entre o fim da república e o início do império; apresentando-o então como «agregato di uomini» que expressam a sua vontade por meio das suas formas organizativas. Dentro desse quadro, o conceito apresenta-se com duas acepções: como conjunto de cidadãos em sentido amplo; e como conjunto de cidadãos reunidos em assembleia. ${ }^{13}$

C) Catalano ${ }^{14}$ remonta a uma concepção rousseauniana de povo, considerando o trabalho de Jhering ${ }^{15}$, e aquele de Gierke ${ }^{16}$; o autor evidencia o aspecto de pluralidade de homens intrínseco ao conceito de populus: «Populus non significa semplicemente l'unità, bensì anche la pluralità di una 'moltitudine' di uomini organizzati». Essa concepção não se apresenta, porém, como o único significado de populus, mas se torna o elemento base para a compreensão de populus como homens reunidos em assembleia.

Diante dessas correntes relativas à concepção política de povo, surgem outros níveis de debate relativos à composição do povo e às prerrogativas do povo em assembleia, delineando o seu papel na constituição romana. A composição do povo, em período arcaico, é apresentada pela doutrina por meio das seguintes correntes:

A) a primeira delas limitando a concepção de povo ao conjunto de pessoas que teria a cidadania, concedida somente ao elemento gentilício. Nesse sentido, o povo reunido em assembleia mantém o caráter gentilício da mesma, como acontece nas teorias propostas por Mommsen ${ }^{17}$ e por De Martino ${ }^{18}$;

10 A concepção de populus enquanto «Staat» remonta a HEGEL, Georg W. F. Lezioni sulla filosofia della storia III. Trad. G. Calogero C. Fatta. Florença: Bompiani, 1963, p. 417 ss.). Como constata Catalano é característico na linha historiografica que segue Rubino a aplicação rígida de categorias modernas como "Estado", "soberania" e "representação"; anulando assim a contraposição histórica entre povo, senado e magistrado. Ver CATALANO, Populus Romanus Quirites, p. 46 s.

11 A doutrina italiana segue essa linha historiográfica com variações em Coli e Grosso. Usando também o conceito de «Staat», como relativo, porém, a res publica encontra-se DE MARTINO, Francesco. Storia della costituzione I. Napoli: Jovene, 1973, p. 98 e passim.

12 A crítica sobre a identificação entre populus e «Staat» foi feita parcialmente, como denota Catalano, já por Gierke (Das deutsche Genossenschaftsrecht III. Graz: Akademische Druck- und Verlagsanstalt, 1954 , p. 43 ss.) e por Costa (A proposito di alcuni recenti studi sulle azioni popolari romane. in RISG XI (1891), p. 366) em base a Jhering, que faz uso do termo Staat de forma substancialmente diversa daquela de Mommsen. Ver: JHERING, Rudolph. Geist des römischen Rechts I. Leipzig: Breitkopf\&Härtel, 1877, p. 107 s.; seguindo as críticas do Jhering: KUNKEL, Wolfgang. Linee di storia giuridica romana. Napoli: Edizioni Scientifiche Italiane, 1972, p. 11.

13 ORESTANO, Riccardo. Il problema delle persone giuridiche in diritto romano. Torino: Giappichelli, 1967, p. 214: «Il dirsi civis, più che indicare uno status rispetto a un ordinamento considerato come distinto dai suoi componenti, equivalse per lungo tempo a dichiarsi parte costitutiva di quel corpus ex distantibus che era il populus Romanus». Ver ibidem, p. 204 ss; esp. 209 e 217 e CATALANO, Pierangelo. Populus Romanus Quirites, p. 45 ss e 59 ss.

14 CATALANO, Pierangelo. Populus Romanus Quirites, p. 116.

15 JHERING, Rudolph. Geist des römischen Rechts I, p. 107 ss.

16 Denota Catalano que o autor alemão através do uso da categoria «Genossenschaft» analisa a relação cidadão-povo, e afirma o conceito de populus Romanus como totalidade dos cidadãos reunidos, ou pensada como reunidos em assembléia. GIERKE, Otto F. v. Das deutsche Genossenschaftsrecht, p. 49 ss.

17 MOMMSEN, Theodor. Römische Staatsrecht III, p. 03: «so dass die Bürgerschaft im rechtlichen Sinn gebildet wird durch die Gesammtheit der zur Zeit vorhandenen freien Geschlechtsgenossen, der quirites, später cives.» O povo demonstra-se nessa interpretação como soberano e investe o rei no seu poder, assimilável a uma magistratura única e vitalícia. A plebe passou a participar ativamente das decisões tomadas em assembléia somente com a reforma serviana. Ver: CARLE, Giuseppe. Le origini del diritto romano. Torino: F.lli Bocca, 1888, p. 180; ss. COSTA, Emilio. Storia del diritto pubblico romano. Firenze: Barbera, 1906, p. 49.

18 DE MARTINO, Francesco. Storia della costituzione I, p. 89 ss.: «Entrambi i organi di questa primitiva comunità di villaggio erano esclusivamente patrizi, il che significa che il popolo era costituito ancora 
B) a segunda, afirmando a ausência em época mais antiga do exclusivismo da cidadania como elemento de composição do povo, como manifesta Bellini. ${ }^{19}$ Com orientação diversa, mas sempre voluntarista, Catalano ${ }^{20}$ afirma a composição do populus por homens, que vivem de acordo com o direito romano. ${ }^{21}$ Nesse sentido, também se manifesta Amirante ao afirmar que a aplicação do conceito de civis expande-se aos latinos, devido à comunhão de direito e religião. ${ }^{22}$

A hipótese sustentada por Mommsen ${ }^{23}$ e por De Martino ${ }^{24}$, afirmando a fundação da cidade com a divisão da população em duas categorias (plebeia e patrícia), sendo a plebe excluída da cidadania por não pertencer à federação originária das gentes, não encontra respaldo nas fontes que tratam do período régio. 0 próprio De Martino ${ }^{25}$ reconhece que a sua proposta de estrutura federativa é incompatível com a tradição da fundação de Roma.

Nesse sentido, Plutarco, Floro, Lactancio, Eutropio, Agostinho e Columela, ao tratarem da fundação da cidade e da formação do povo romano, prescindem do elemento gentilício e não tratam de cidadania. ${ }^{26}$

Catalano propõe, então, como conceito de povo "una 'multitudine' avente certe caratteristiche. Non si tratta di una cosa 'personificata', quale lo 'Stato'"127. O "povo" passa a ser apresentado como algo concreto, permitindo uma abstração somente como unidade, ou seja, conjunto de homens. Não se condiciona pelo elemento gentilício, como portador de cidadania, mas se fundamenta no voluntarismo da multidão e, consequentemente, dos homens em viver de acordo com o direito romano 28 .

soltanto da coloro che appartenevano ai grandi gruppi gentilizi».

19 BELLINI, Vincenzo. Sulla genesi e la struttura delle leghe nell'Italia arcaica, in RIDHA, III s. VIII (1961), p. 226 e ss. A interpretação de Bellini identifica-se com alguns aspectos daquela de Jhering, que partindo da tradição relativa à origem de Roma entende o povo romano como formado por homens provenientes de diferentes origens. JHERING, Rudolph. Geist des römischen Rechts I, p. 94 ss.

20 CATALANO, Pierangelo. Promemoria, in XXVII Seminario Internazionale di Studi Storici "Da Roma alla terza Roma". Roma, 2007. Em relação à cidadania o autor evidencia o princípio de civitas augescens e civitas amplianda já na concessão da cidadania através do asilo no Capitólio e junto à manumissio dos escravos, considerando a plebe, enquanto conjunto de homens não ligado a nenhuma gens, também como cives e portanto, como partes do povo. Ver: Id. Populus Romanus Quirites, p. 116 ss.; Id. Seduta preliminare, $\mathrm{p}$. XXII s.

21 CATALANO, Pierangelo. Alcuni concetti e principi giuridici romani secondo Giorgio La Pira, in II ruolo della buona fede oggettiva nell'esperienza giuridica storica e contemporanea. Padova : CEDAM, 2003 , p. 101. Como consequência dessa concepção o direito romano não é feito para os cidadãos romanos, mas para os homens, evidenciando o seu universalismo. Em contrapartida constata o autor uma forte política de concessão da cidadania que concebe o "ser romano" por meio do viver de acordo com os costumes e a cultura romana, ver Cic. rep. 1,39 e Alf. dig. 5,1,76.

22 Amirante (Una storia giuridica di Roma, Napoli: Jovene, 1991, p. 109 ss), baseando-se no relato de Lívio e Strabão, analisa a aceitação de estrangeiros como reis de Roma e conclui que: «Non potrebbe essere più chiaro che qui peregrinus sta ad indicare colui che non è latino, che appartiene ad altro diritto e ad altri culti. E per converso come cives 'concittadini', coloro che hanno in comune diritti e religione».

23 MOMMSEN, Theodor. Römische Staatsrecht, III, p. 5 ss.

24 DE MARTINO, Francesco. Storia della costituzione romana. Napoli: Jovene, 1973, I, p. 79 e 106 ss.

25 DE MARTINO, Francesco. Storia della costituzione romana. Napoli: Jovene, 1973, I, p. 106.

26 Plutarco (Rom. 9,3), Floro (Epit. 1,1,9), Lactancio (inst. 2,6), Eutropio (Brev. 2,1), Agostinho (civ. $1,34)$ e Columela (r.r. 1 praef. 18). De forma pouco clara Dionísio de Halicarnasso $(2,9,2)$ afirma que Rômulo confiou os plebeus aos patrícios, não identificando a composição das duas categorias. Sobre cidadania romana, ver CRIFÒ, Giuliano. Cittadinanza (diritto romano). Enciclopedia del diritto VII. Milano: UTET, 1960, p. 1 ss.; CRIFÒ, Giuliano. Civis. La cittadinanza tra antico e moderno, p. 23 ss. Sobre Asilo: CRIFÒ, Giuliano. Asilo (diritto di). Enciclopedia del diritto III, 1958, p. 191 ss.

27 CATALANO, Pierangelo. Alcuni concetti e principi giuridici romani secondo Giorgio La Pira. In: Il ruolo della buona fede oggettiva nell'esperienza giuridica storica e contemporanea, p. 101.

28 Sêneca (ira, 2,31,7) transcende à cidadania através do universalismo, ao tratar da pátria em base a concepção de pertença a uma "cidade" ainda maior : "Nefas est nocere patriae; ergo ciui quoque, nam hic pars patriae est - sanctae partes sunt, si uniuersum uenerabile est; ergo et homini, nam hic in maiore tibi urbe ciuis est. Quid si nocere uelint manus pedibus, manibus oculi? Vt omnia inter se membra consentiunt quia singula seruari totius interest, ita homines singulis parcent quia ad coetum geniti sunt, salua autem esse societas nisi custodia et amore partium non potest". Nesse sentido, o jurista Alfeno (dig. 5,1,76), compara o povo a um corpo, que pela sua espécie defini-se como tal, independente da mudança das suas partes. 
O termo "multidão" denota o reconhecimento de todos os seres humanos (homens e mulheres) como parte do populus. Tal fato, somado à abertura da comunidade dentro da liga latina ainda em tardo período régio, demonstra independência em relação a um conceito exclusivista ou étnico de cidadania. Essa, em período arcaico, era baseada em uma concepção universalista ou voluntarista, que reconhecia aos habitantes de Roma, independente de suas origens, a possibilidade de fazer parte do direito romano. ${ }^{29}$ Nesse sentido, Bellini ${ }^{30}$ afirma que havia originariamente uma relação de igualdade entre as comunidades, permitindo um contínuo intercâmbio dos seus elementos constitutivos.

Tal teoria implica a ausência em época mais antiga de uma imposição racial no que concerne a cidadania. Ser cidadão "implique la volonté politique qui fait d'un homme un quirite, c'est-à-dire le rend partie $d u$ populus Romanus Quirites ${ }^{131}$. É, consequentemente, viver de acordo com o direito romano. Com isso, Roma passa a valorizar, então, uma forte política de concessão da cidadania baseada no viver de acordo com o direito e a cultura romana. ${ }^{32}$

Os princípios de civitas augescens e civitas amplianda presentes no universalismo romano - para a concessão da cidadania -, por meio do instituto de asilo de Rômulo no Capitólio33, manifestandose também na manumissio dos escravos, bem como no fato de a plebe ser vista, como conjunto de homens não ligado a nenhuma gens, também como cives e, portanto, como partes do povo ${ }^{34}$. Tal fenômeno faz com que o elemento voluntarista presente a partir da fundação de Roma - voltado, sobretudo a construção de um povo enquanto conjunto de cidadãos - conduza a uma concepção universalista de cidadania que, por sua vez, gera uma concepção universalista do direito romano, feito não somente para os romanos, mas para os homens.

29 Essa mesma concepção universalista, embora com novos instrumentos, se fará presente em 212 d.C. com o edito de Antonino Caracala, que expande a cidadania, salvo exceções, a todos os habitantes do império.

30 BELLINI, Vincenzo. Sulla genesi e la struttura delle leghe nell'Italia arcaica, p. 226: "Nell'assenza per l'epoca più antica di un esclusivismo cittadino (che solo lentamente si verrà maturando), le comunità tribali si trovano su un piede di parità, che permette un continuo interscambio dei loro elementi. Dei re di Roma, escludendo i mitici fondatori Albani, Tullo è di Medulia, Numa e Anco di Cures. Assumendo che sotto i fatti storici si nasconda un fondamento storico, può supporsi che cosi si localizzassero nell'oppidum romano capi di formazione più vaste, comprensive delle località di origine, ovvero che il sentimento comunitario rendesse facile l'interscambio degli elementi dirigenti: probabilmente le due cose allo stesso tempo, in una realtà che può suporsi fluida e non definita. (...) sotto questo punto di vista il Ius Latii dell'epoca storica non sarebbe la condizionata e limitata estensione alle comunità sociae dei diritti della civitas, ma è il sopravvivere di un'eguaglianza sociale che, al sovvraporsi della organizzazione cittadina e nel processo di giuridicizzazione del costume, permane sotto la forma di un privilegio concesso dalla città egemone". O autor indica como trabalho anterior com a mesma concepção: SHERWIN WHITE, Adrian Nicholas. The Roman citizenship. Oxford: Clarendon Press, 1939, p. 10. Concordando com Bellini sobre a fluidez do "stato di cittadinanza" SERRAO, Feliciano. Diritto privato economia e società. Napoli: Jovene, 2006, p. 204. Em contraposição, Ellul entende que a igualdade ocorre somente entre as cidades latinas desde o inicio por conta da origem religiosa em comum. Os latinos, provenientes de Alba terminam por ter instituições próximas e que os permite de usar um direito comum. ELLUL, Jacques. Histoire des institutions. L'Antiquité. Paris: Quadrige/PUF, 1999, p. 232.

31 CATALANO, Pierangelo. Seduta preliminare. Seminari Internazionali di Studi Storici "Da Roma alla Terza Roma" (La nozione di "romano" tra cittadinanza e universalità). Napoli: Ed. Scientifiche Italiane, 1982, p. XXII; Alcuni concetti e principi giuridici romani secondo Giorgio La Pira. Il ruolo della buona fede oggettiva nell'esperienza giuridica storica e contemporanea, p. 101. Ver Cic. rep. 1,39 e Alf. dig. 5,1,76.

32 Nesse sentido, também se manifesta Amirante ao afirmar que a aplicação do conceito de cives expandese aos latinos, devido à comunhão de direito e religião. Amirante (Una storia giuridica di Roma, p. 109 ss.) baseando-se no relato de Lívio e Strabão analisa a aceitação de estrangeiros como reis de Roma e conclui que: "Non potrebbe essere più chiaro che qui peregrinus sta ad indicare colui che non è latino, che appartiene ad altro diritto e ad altri culti. E per converso come cives 'concittadini', coloro che hanno in comune diritti e religione".

33 Liv. 1, 8, 4. O "asilo no Capitólio" foi criado por Rômulo para a concessão da cidadania à pessoas estrangeiras, em geral banidas ou fugidas das cidades vizinhas, e visava aumentar a população de Roma.

34 CATALANO, Pierangelo. Populus Romanus Quirites, p. 116 ss.; CATALANO, Pierangelo. Seduta preliminare. Seminari Internazionali di Studi Storici "Da Roma alla Terza Roma" (La nozione di "romano" tra cittadinanza e universalità), Ed. Scientifiche Italiane,1982, p. XXII s. 
Essa concepção sofreu modificações a partir do final do reino e metade da república. Neste período, o reconhecimento de igualdade entre os elementos das comunidades passou a ocorrer apenas entre as cidades latinas e revestindo-se daquilo que se tornaria o ius latii. Tem-se dessa forma uma nova concepção de civitas, com a consolidação da unidade composta pelas partes. ${ }^{35}$ Mesmo com essa limitação, permanecem indícios da abertura originária do sistema romano por meio da Lei das XII tábuas, denotando a participação do estrangeiro ao ius. ${ }^{36}$

O gênero "não cidadão" abarcava diferentes espécies que iam do estrangeiro que não pertencia a um povo em guerra com Roma e que não era ligado a Roma por um particular tratado ou vínculo étnico, ao estrangeiro ligado a Roma pelos foedera; aos grupos que por circunstâncias e motivos diferentes tinham encontrado asilo na cidade, aos habitantes das cidades latinas ligadas à Roma por tratados e por vínculos étnicos, aos quais era reservada uma posição privilegiada, visto que constituíam um status intermediário entre cives e peregrini, com subdivisões no que refere-se ao exercício de direitos. ${ }^{37}$

Esse mosaico de relações pode ser mais facilmente compreendido se partirmos da constatação de que no período republicano a distinção do status jurídico das pessoas em relação ao povo romano era de três tipos: cives Romani, ou seja, todos aqueles reconhecidos como cidadãos romanos; latini, habitantes das cidades latinas que faziam parte do foedus latinum; peregrini, pessoas que não fossem cives ou latini. ${ }^{38}$

\section{AS GUERRAS DE EXPANSÃO ROMANA E O ENRIJECIMENTO DA ASSIMILAÇÃO DO ESTRANGEIRO}

Na Roma antiga, o termo mais antigo usado para indicar o estrangeiro é hostis. Na sua origem, este conceito não apresentava conotação negativa, tratando apenas da constatação da não pertença de alguém à comunidade romana. ${ }^{39}$

35 Assim a ideologia de uma comunidade unitária encontra suas raízes no mundo etrusco, sendo posteriormente transmitida para Roma. SERRAO, Feliciano. Classi, partiti e legge nella repubblica romana. Pisa: Pacini, p. 19; NOCERA, Guglielmo. Il binomio pubblico-privato nella storia del diritto. Napoli: Edizioni Scientifiche Italiane, 1992, p. 14. Tondo afirma que populus e plebs apresentam-se então como aspecto militar e social do mesmo elemento constitucional (TONDO, Salvatore. Profilo di storia costituzionale romana. Milano: Giuffrè, 1981, I, p. 83 ss. esp. 86). Povo e senado apresentam-se então como elementos fundamentais para o enquadramento da população romana. Com diferente leitura sobre a expressão populus plebes que: CATALANO, Pierangelo. La divisione del potere in Roma (A proposito di Polibio e Catone). Studi in onore di Giuseppe Grosso VI. Torino, 1974a, p. 682: "populus plebesque indica il crescente potere della parte plebea, populus plebesve la raggiunta parificazione sul piano del potere normativo e cioè I'assimilazione della 'parte' nel 'tutto'". A teoria afirmada por Tondo remonta de certa forma àquela de Niebuhr, que interpreta a expressão populus Romanus Quirites com idêntico significado de populus plebes que Romana. Como manifesta Catalano (populus Romanus Quirites, p. 24) o Niebuhr usa «Volk» seja para indicar a plebs, seja para indicar a multidão. NIEBUHR, M. Barthold Georg. Römische Geschichte. Berlin, 1811, I, p. 373 ss.

36 Gell. noct. att. 20,1,47 (FIRA, tab. III, 5); "tratados" que limitavam o comércio (como aquele de Cartago) e Festus, Status dies p. 314 L. Sobre o assunto ver: CATALANO, Pierangelo. Linee del sistema sovrannazionale romano. Torino: Giappichelli, 1965, p. 66 ss; CATALANO, Pierangelo. Populus Romanus Quirites, 1974, p. 140 ss.

37 SERRAO, Feliciano. Diritto privato economia e società. Napoli: Jovene, 2006, p. 347. Várias eram as distinções quanto aos peregrinos no que se refere às limitações ao exercício de direitos. Aos possuidores de melhores condições era reconhecido o direito ao commercium e ao connubium com os romanos e com os latinos, assim como o direito ao testamenti factio, ou seja, de ser nomeado herdeiro de testamento de um cidadão romano. Por serem considerados para todos os efeitos estrangeiros, em sua grande maioria os peregrini não estavam sujeitos ao direito romano, mas sim ao ius gentium aplicado pelo pretor peregrino.

38 CERAMI, Pietro et CORBINO, Alessandro. Storia del Diritto Romano. Messina: Rubettino, 1996, p. 104.

39 Ver ERNOUT, Alfred. MEILLET, Antoine. Dictionnaire étymologique de la langue latine. 1, Paris: C. Klincksieck, 1959, p. 301; BENVENISTE, Émile. Le vocabulaire des institutions indo-européennes, I. Économie, parenté, société. Paris: Minuit, 1969, p. 93. 
Catalano ${ }^{40}$ evidenciou a existência de diferentes teses no que concerne à tutela jurídica prestada ao não romano no âmbito do ordenamento romano. Por primeiro, tem-se a tese da hostilidade natural, que remonta a Mommsen, asseverando que em época primitiva estivesse em vigor o princípio da ausência de direito do estrangeiro fora dos limites da sua cidade. Tal princípio somente sofreria uma flexibilização por meio do instituto de hospitium privado. Em posição contrária, Frezza ${ }^{41}$ rejeita a tese de hostilidade natural, mas entende que havia restrições aos estrangeiros antes do III a.C. Uma terceira posição, ainda, representada por Heuss ${ }^{42}$, afirma a existência de um comércio internacional também na ausência de tratados. Nessa direção, afirma também De Martino que, tendo por base a fides, o estrangeiro poderia ser juridicamente tutelado por parte dos tribunais romanos. Em relação ao período mais antigo, tendo por base pesquisas sobre o ius fetiale, não haveria para os romanos a impossibilidade de que os estrangeiros, mesmo não ligados a Roma por tratados, fossem sujeitos de atos solenes e de relações consideradas pelo $i u s^{43}$.

Neste período, formado pela comunidade gentilícia até a consolidação da civitas, entende-se que provavelmente não houve uma clara distinção do ponto de vista jurídico entre romano e não romano, sendo possível que este último viesse a fazer parte do ius. Recorda-se que a maior parte dos não romanos presentes neste período em Roma, são provavelmente pessoas de cultura latina e, consequentemente, têm comunhão cultural com os romanos. Assim sendo, o ius romano, baseado na sua natureza universalista, abarcaria tanto romanos, quanto não romanos, dentro de uma maior ou menor tutela, de acordo com a existência ou não de específicos foedera. ${ }^{44}$ Esta concepção jurídica de direitos do não romano pode, ainda, ser encontrada na Lei das XII tábuas ${ }^{45}$, assim como se encontra nos escritos de Gélio (noct. att. 16,4,4.) e de Festo (v. Status dies <cum hoste> p. 414-416 L.).

Nell'epoca più antica lo straniero in generale era indicato con hostis, mentre il "nemico" era perduellis. Solo in un secondo momento lo straniero verrà designato come peregrinus e si affermerà l'uso di hostis nel senso di "nemico", ossia di indivíduo appartenente ad un stato di guerra con Roma. ${ }^{46}$

A abertura de Roma ao estrangeiro, fruto da cultura universalista, também presente no ius e que facilitava a concessão da cidadania Romana -, foi indicada por Lívio por meio do Asilo no Capitólio (Liv. 1,8,4) e da própria formação da cidade. Esta mesma, contudo, provavelmente foi modificada entre o final do reino e a metade da república. Observa-se tal fato devido à mudança no significado do termo hostis. Esse, inicialmente, significava "estrangeiro", passando com o tempo a adquirir outro significado, ou seja, aquele de "inimigo".

Segundo De Martino ${ }^{47}$, uma hipótese relativa a esta mudança é o longo período de guerras de expansão nas quais Roma esteve envolvida. Este provavelmente acabou por desencadear um processo que conduziu a um rompimento com a abertura romana ao estrangeiro, afetando, consequentemente, a política flexível de concessão da cidadania. A mudança é atribuída ao período posterior à emanação das XII tábuas, provavelmente nos anos das guerras de expansão na Itália, evidenciando a impossibilidade de especificar como e por quais causas tal fenômeno ocorreu. ${ }^{48}$

40 CATALANO, Pierangelo. Linee del sistema sovrannazionale romano, p. $53 \mathrm{ss}$.

41 FREZZA, Paolo. L'Età classica della costituzione repubblicana. Labeo, 1, 1955, p. 323 ss.; FREZZA, Paolo. Ius gentium. RIDA, 2, 1949, p. 268 ss. Na mesma linha PARADISI, Bruno. Storia del diritto internazionale nel Medio Evo. Milano: Giuffrè, 1940, p. 31 ss.; PARADISI, Bruno.Osservazioni sul rapporto storico tra diritto internazionale pubblico e diritto internazionale privato. Studi Senesi 59, 1945, p. 268 ss.

42 HEUSS, Alfred. Die völkerrechtlichen Grundlagen der römischen Aussenpolitik in Republikanischer zeit. Leipzig: Dieterich, 1933, p. 7.

43 CATALANO, Pierangelo. Linee del sistema sovrannazionale romano, p. 65.

44 Ver o foedus Cassianum entre romanos e latinos em 493 a.C. e os dois foedera de Roma com Cartago em 509 a.C. e 348 a.C. De forma contrária, Capogrossi Colognesi entende que o forte interesse das partes no Tratado de Cartago em prover a tutela dos seus cidadãos que venham a encontra-se no âmbito de influência da contraparte, "mostra tuttavia che solo un apposito accordo internazionale poteva vincolare gli ordinamentistatali dell'epoca a fornire una adeguata protezione giuridica agli stranieri". COLOGNESI, Luigi Caprogrossi. Lezioni di storia del diritto romano. Monarchia e Repubblica. Napoli: Jovene editore, 2004, p. 79.

45 Ver Tab. I,5; II, 2: VI,4.

46 SERRAO, Feliciano. Diritto privato economia e società, p. 344.

47 DE MARTINO, Francesco. Storia della costituzione romana. Napoli: Jovene, 1973, p. 20.

48 Sobre a mudança de significado do termo hostis ver: BENVENISTE, Émile. Le vocabulaire des institutions indo-européennes, p. 93. 
Por conta desta mudança em relação ao estrangeiro, é possível observar a modificação dos requisitos para a concessão da cidadania romana, passando a ser regulada da seguinte forma :

a) por nascimento: de um casamento válido, sendo o pai cidadão romano no momento da concepção, mesmo que a mãe não seja cidadã ${ }^{49}$; de mãe romana, fora de uma casamento válido. Se a criança não nasceu de um casamento válido, de acordo com o direito romano, ela segue a condição jurídica da mãe ${ }^{50}$; ao filho de peregrinos, se antes do nascimento, seja estada concedida a cidadania, seja a ambos os genitores, seja somente ao pai, se a mãe tenha obtido ao menos o connubium, condição necessária para o matrimônio legítimo.

b) após o nascimento: por concessão individual e estritamente pessoal; por concessão coletiva; por consequência automática do verificar-se de certas condições como, por exemplo, o domicílio em Roma de um Latino; ou no caso do escravo, por manumissão por parte do dominus.

O aumento do campo de regulação das normas voltadas à concessão da cidadania reflete não apenas o enrijecimento da relação com o estrangeiro, assim como a maior preocupação no que se refere aos direitos concernentes à cidadania, levando até mesmo à guerra de Roma com seus aliados.

\section{AS PRERROGATIVAS DOS LATINOS}

Os antigos latinos eram um conjunto de populações afins que no $1^{\circ}$ milênio a.C. se fixaram na região do Latio. Acredita-se que eles eram agricultores que procuravam defender-se dos ladrões das montanhas vizinhas. Nesta perspectiva, os povos latinos organizaram-se em vilarejos protegidos por muros e participavam de um "sistema confederativo", chamado de liga latina, contra os inimigos, seguindo o exemplo etrusco. A liga era composta por cerca de trinta cidades e seu centro religioso era no Monte Albano, onde se realizava o culto a Giove Laziare. A liga latina era regida por meio de uma Assembleia da confederação, com representantes dos povos latinos, que se reuniam algumas vezes por ano em Ariccia. As decisões tomadas em assembleia eram concernentes a declarações de guerra, realizações de acordos de paz, alianças com outros povos, e escolha da cidade que deveria comandar o exército da liga latina.

A doutrina atualmente dominante considera as relações privadas entre latinos (incluídos os romanos) pressupostas e anteriores à civitas. Estas teriam por base uma comunidade originária cultural e jurídica, que, embora fragmentada em cidades, mantinha fortes vínculos. A comunidade de cidades latinas deve, portanto, ser contemplada como uma comunidade natural de direito. ${ }^{51}$

49 "O que temos falado a respeito do fato que aquele que nasce de uma cidadã Romana e de um peregrinus, entre os quais não existe matrimônio, nasce peregrinus, é estabelecido pela Lei Mincia. Esta dispõe, também, que este segue a condição do genitor mais desavantajado. A mesma lei, de fato, dispõe que, quando, ao contrário, um peregrinus tenha pegado como esposa uma cidadã Romana com a qual não existia matrimônio, aquele que nasce de uma tal união seja peregrinus. A Lei Mincia é particularmente oportuna neste caso: na ausência desta lei, de fato, seria indevido derivar um outro status. Já o que nasce daqueles entre os quais não existe matrimônio aquista o status da mãe, segundo o direito das gentes. Mas, é supérflua aquela parte da lei onde vem estabelecido que, de um cidadão Romano e de uma peregrinus, nasce um peregrinus. Este, de fato, seria peregrinus segundo o direito das gentes também na ausência de tal lei. Isto vale somente para as nações e as gentes estrangeiras, mas também para quantos são chamados Latini, que tinham próprios povos e próprias cidades e eram contados entre os peregrini. Pelo mesmo motivo, ao contrário, nasce um cidadão Romano de um Latino e de uma cidadã Romana, seja o matrimônio contraído em base a Lei Elia Senzia seja de outro modo. Mas, alguns tiveram que, de um matrimônio contraído em base a Lei Elia Senzia, nascesse um Latino, já que se considerava que, neste caso, o matrimônio entre eles fosse concedido pelas Leis Elia Senzia e Iunia e que, sempre, o matrimônio faz com que aquele que nasce siga o status do pai. Quando, ao invés, o matrimônio tenha sido contraído de outro modo, aquele que nasce, segundo o direito das gentes, segue o status da mãe, e é, por tanto, cidadão Romano. Mas, segundo o direito vigente em base a um senatoconsulto emanado por proposta do divo Adriano, aquele que nasce de um Latino e de uma cidadã Romana é de qualquer modo cidadão Romano". Gaio. inst. 1, 78-80.

50 Conforme nos lembra Giuliano Crifò (Civis. La cittadinanza tra antico e moderno, p. 33), nos casos em que o filho segue a condição da mãe: "è cittadino se la madre è cittadina al momento del parto, non lo è se la madre lo era in gravidanza, ma ha cessato di esserlo al momento del parto, nè lo sarà, alla fine della repubblica, se nasce da una cittadina e da un Latino o peregrino (Lex Minicia)".

51 CATALANO, Pierangelo. Linee del sistema sovrannazionale romano. Torino: Giappichelli, 1965, p. 56 e s. 
A cultura romana é claramente uma cultura latina, composta por elementos religiosos, linguísticos e consuetudinários interligados. Dentro desta perspectiva, o primeiro intercâmbio de membros entre as comunidades ocorreu entre os romanos e os latinos, devido a questões territoriais e culturais. A antiguidade das relações entre Roma e os povos do Latio são atestadas pelo uso do conceito ius Quiritium ainda em idade imperial para indicar o direito que regula a cidadania romana no que tange à concessão aos latinos.

O status jurídico de latino é, portanto, autônomo, caracterizado por alguns direitos de cidadania e fruto de um vínculo étnico-cultural com o povo romano, explicável pela obtenção da cidadania romana ao verificar-se o estabelecimento do seu domicílio em Roma.

Roma, como parte da liga latina, paulatinamente conquistou poder na região do Latio, ao ponto de conseguir paridade com a liga, em direitos e obrigações por meio do foedus Cassianum de 493 a.C. As cidades latinas aliadas comprometeram-se, desde o foedus Cassianum, a não realizar a guerra e nem a ajudar o inimigo, ficando estabelecida a ajuda recíproca de guerra, a divisão pela metade dos saques de guerras comuns e fixava a resolução das controvérsias relativas aos negócios entre membros das comunidades aliadas em dez dias. ${ }^{52}$

Na guerra contra a liga latina, entre 340 e 338 a.C., Roma foi vencedora e a liga foi dissolvida. As instituições da liga latina desapareceram e Roma estabeleceu com as cidades latinas tratados diferentes, de acordo com o comportamento de cada cidade durante a guerra. Algumas cidades são incorporadas a Roma e com outras Roma realiza foedera iniqua em geral esses foedera proibiam exercitar o ius belli et pacis contra outras cidades federadas com Roma. Do mesmo modo, impôs às cidades vencidas que participassem das guerras ao lado de Roma, as proibiu de criarem alianças entre si e de realizarem comércio e casamentos entre pessoas de diferentes cidades. As cidades conservavam a sua soberania, o seu direito, tinham os próprios órgãos, jurisdições, alistamentos, censo e também moeda, mas a sua política era aquela imposta por Roma. A paridade se mantinha apenas no campo religioso. ${ }^{53}$

Mesmo com tais constrições, os latinos continuaram a ter uma posição privilegiada nas relações com Roma em relação aos outros aliados. A condição dos mesmos não ficou limitada aos velhos habitantes do Lácio e às suas colônias, mas com o tempo foi expandida, à medida que Roma fundava colônias latinas ou quando concedia a latinidade, como posição privilegiada em relação aos peregrinos. A categoria 'latino', mesmo tendo sido dividida em prisci (ou veteres), habitantes das cidades latinas federadas com Roma, e os coloniarii, habitantes das colônias latinas, mantinha prerrogativas particulares como ius connubii, direito de contrair matrimônio válido com pessoa com cidadania romana; ius commercii, direito de comerciar com os cidadãos romanos; ius migrandi, direito de tornar-se cidadão romano ao domiciliar-se em Roma. ${ }^{54}$

\section{A POLÍTICA DE EXPANSÃO DA CIDADANIA: ENTRE REPÚBLICA E IMPÉRIO} ROMANO

A política de extensão da cidadania tem sua origem quando inicia o processo de abertura da civitas por meio do asilo de Rômulo no Capitólio, e tem continuidade mesmo em fases de enrijecimento constatadas em Roma durante república e império, paralelamente às guerras de expansão romana.

As sucessivas guerras nas quais Roma encontrou-se desde o reino a levaram a unificar a Itália sob a sua hegemonia durante a república. Para construir esta hegemonia, Roma estabeleceu diferentes relações com as comunidades e as federações as quais se sobrepôs. De acordo com Grosso, pode-se observar que a expansão de Roma na Península itálica seguiu dois sistemas fundamentais: o sistema federativo e o sistema da extensão territorial por meio da anexação. Ambos os sistemas, de federação e de anexação, eram baseados em foedera, pactos entre Roma e a comunidade ou federação. ${ }^{55}$

52 GROSSO, Giuseppe. Lezioni di Storia del diritto romano. Torino: Giappichelli, 1965, p. 238.

53 GROSSO, Giuseppe. Lezioni di Storia del diritto romano, p. 238.

54 GROSSO, Giuseppe. Lezioni di Storia del diritto romano, p. 240 . Em 19 d.C. foi criado o status jurídico de Latinus Iunianus, por meio da Lex Iunia Norbana, que concedia aos manumitidos "informalmente" algumas prerrogativas.

55 Quanto às federações era tendência de Roma disolvê-las, realizando pactos particulares com cada 
As comunidades itálicas poderiam em geral ter entre elas o ius commercium, o ius connubii e o ius migrandi. A proibição de estabelecimento destes direitos entre as comunidades latinas era, porém, imposto por Roma por questões políticas.

As comunidades que passaram a fazer parte do território de influência romana por meio da anexação, e não da federação, podiam receber a concessão da civitas optimo iure, mas em sua maioria recebiam a concessão da civitas sine suffragio, uma espécie de cidadania com restrições ao direito de voto e que garantia aos seus portadores um mínimo de direitos em relação a Roma.

Com a incorporação de uma comunidade em Roma e com a consequente atribuição da cidadania cum ou sine suffragio, esta deixava de ser uma civitas em si. Desaparecia uma possível cidadania de origem, tornando os seus cidadãos apenas cidadãos romanos. Estas cidades mantinham, porém, um status de autonomia e eram denominadas municipia. O termo municipium origina-se de munus capere, referindo-se à assunção dos deveres dos cidadãos, fato que se refletia particularmente nas comunidades que recebiam a civitas sine suffragio. Em geral esta última era anexada por deditio, ou seja, entrega sem imposição de condições pela comunidade a Roma; enquanto as cidades com civitas optimo iure geralmente tinham tal status por meio de dispositivo previsto em foedus, ou seja, pacto realizado entre Roma e a comunidade, em que vinha definido a sua adesão à cidadania romana. ${ }^{56}$

Os municipes optimo iure, pertencentes a territórios anexados a Roma, eram cidadãos a pleno título e gozavam de todos os direitos de cidadania, em direito privado e em direito público. A concessão deste tipo de cidadania e a realização do foedus refletem a importância da comunidade, bem como o fato dessa poder ter certa autonomia, conservando leis, instituições jurídicas e políticas próprias. ${ }^{57}$

Os municipes sine suffragii iure não tinham, contudo, o eleitorado passivo e ativo. Cabia-lhes principalmente o ônus da cidadania, visto que na Roma antiga dá-se mais valor à liberdade pública do que à liberdade privada. ${ }^{58}$ Ademais, esses municípios podiam ou não possuir o ius commercii e o ius connubii com os romanos, delineando uma concessão parcial de direitos da cidadania. ${ }^{59}$

Além dos municipia, há outros aglomerados de cidadãos. É o caso dos conciliabula, os fora, os vici e os castela ${ }^{60}$, bem como as coloniae de cidadãos ou de latinos introduzidas por Roma em território conquistado. Tais colônias eram comunidades fundadas e organizadas por Roma com o objetivo de assegurar a defesa e controlar povos hostis ${ }^{61}$. Os modelos de colônias, compostas por cidadãos ou por latinos, refletiam formas de administracão diferentes. Nas colônias compostas por comunidade. GROSSO, Giuseppe. Lezioni di Storia del diritto romano, p. 240. Os foedera celebrados poderiam ser aequum ou iniquum de acordo com as disposições de cada pacto. O foedus aequum era marcado por um certo equilíbrio entre as disposições de interesse das cidades pactuantes, sendo que o foedus iniquum era marcado pela hegemonia de Roma, que impunha às comunidades de servare maiestatem populi Romani, renunciando ao ius belli et pacis, para obrigar-se a participar com Roma das suas guerras fornecendo contingentes militares e navais. Na prática ambas as comunidades afetadas pelo foedus aequum e pelo foedus iniquum acabavam aceitando a política externa de Roma. A disposição dos foedera influenciava diretamente na política da concessão de direitos relativos à cidadania, neste sentido tem-se que algumas comunidades, como os socii Italici não tinham acesso ao ius commercii, ao connubium e nem o ius migrandi, mas apenas o ius exulandi (faculdade de acolher os exilados das cidades aliadas). Ver, a respeito, GROSSO, Giuseppe. Lezioni di Storia del diritto romano, p. 241.

56 GROSSO, Giuseppe. Lezioni di Storia del diritto romano, p. $241 \mathrm{~s}$.

57 GROSSO, Giuseppe. Lezioni di Storia del diritto romano, p. 242.

58 Ver sobre o tema: CONSTANT, Benjamin. De la liberté des anciens comparée à celle des modernes. Discours prononcé à l'Athénée royal de Paris, 1819, passim.

59 GROSSO, Giuseppe. Lezioni di Storia del diritto romano, p. 243. O termo "semicittadinanza" usado por Grosso não é usado neste artigo devido ao diverso valor atribuído ao mesmo termo por Feliciano Serrao na obra Diritto privato economia e società.

60 Conciliabula eram distritos no campo, não constituíam uma unidade comunal com a qualificação das pessoas originárias. As pessoas dependiam de órgãos do município ou do praefectus da circunscrição a qual pertenciam. Os fora eram aglomerações de cidadãos romanos estabelecidos ao longo das grandes vias romanas. Os vici e os castella eram organizações menores que não superavam o caráter da vila ver: GROSSO, Giuseppe. Lezioni di Storia del diritto romano, p. 244.

61 As coloniae civium Romanorum fundadas na costa eram denominadas também de coloniae maritimae, enquanto aquelas fundadas com o objetivo de compensar aos soldados veteranos eram chamadas de coloniae militares. As colônias romanas inicialmente eram compostas por 300 colonos, mas tem-se conhecimento de algumas que teriam chego a dois ou três mil colonos. 
cidadãos, esses conservavam sua posição de cidadãos optimo iure. A comunidade desenvolvia-se, portanto, com autonomia administrativa e jurisdicional. As colônias latinas seguiam um modelo diferente, formando cidades autônomas ligadas a Roma por um foedus iniquum, mas com tratamento privilegiado por serem latinos.

\section{A EXPANSÃO DA CIDADANIA AOS LATINOS}

O processo de expansão e concessão da cidadania que ocorreu durante a república, desenvolveuse principalmente por meio da rogatio Sempronia de civitate sociis danda, proposta por Caio Graco em 122 a.C. Tal proposta baseava-se sobretudo na fragilidade do vínculo de sujeição, no qual até então eram mantidos os povos aliados de Roma, assim como no descontentamento destes com a condição que Ihes fora imposta. ${ }^{62}$ A reforma, se aprovada, concederia a cidadania romana aos latini e o status de latino aos itálicos. ${ }^{63}$ Tal projeto, contudo, não foi aprovado pelas instituições políticas romanas que, por meio de algumas concessões claramente demagógicas, reconheceram aos latini e aos itálicos outros direitos menos importantes de caráter econômico e tributário.

O problema posto pela fragilidade do vínculo de sujeição dos latini e dos itálicos, porém, continuou sendo latente na sociedade romana, tanto que, no ano de 91 a. C., o tribuno Marco Livio Druso Filho propôs um novo projeto de lei (rogatio Livia de civitate Latinis et sociis danda) tentando resgatar parte da proposta de Caio Graco. A questão desencadeou uma violenta reação por parte da antiga aristocracia romana, que temia o fim dos privilégios mantidos aos cidadãos. A situação complicouse a tal ponto que Livio Druso Filho foi assassinado antes mesmo da votação da sua proposta. Com a morte de Druso, inicia-se, em 91 a. C., a guerra social (bellum sociale), motivada pela busca de melhores condições políticas e jurídicas aos membros das cidades itálicas associadas a Roma, ou seja, as cidades associadas buscam a cidadania romana.

Conforme Lobrano ${ }^{64}$, neste sentido, a

(...) crise ocorrida durante o século primeiro a.C. e que é, justamente, uma crise de crescimento societário (o 'bellum sociale', a guerra com os «associados» itálicos para o aperfeiçoamento da societas) e contribuiu para tomada de consciência pelos Romanos da própria essência de sua república.

A revolta dos aliados itálicos que configura o bellum sociale gerou as concessões romanas tão esperadas em âmbito de cidadania, como delineiam três leis emanadas entre os anos 90 e 89 a. C.:

- A lex Iulia de civitate latinis danda, proposta pelo Cônsul Lúcio J. César aprovada em 90 a. C., concedeu a cidadania romana a todos os Latini e itálicos que durante o conflito se mantiveram fiéis à Roma.

- No ano de 89 a. C., com a lex Plautia Papiria de civitate sociis danda, foi concedida a cidadania à latinos e itálicos, residentes na península itálica, que tivessem declarado ao magistrado romano em até dois meses de querer tonar-se cidadão.

- Ainda em 89 a.C., o cônsul Pompeo Strabão apresentou e conseguiu a aprovação da lex Pompeia de Transpadanis, estendendo o estatuto de latini aos moradores da Gália Transpadana, dando as suas comunidades o status de colônias latinas.

O fim do bellum sociale em 88 a.C. reflete a consciência por parte de Roma da importância de reforçar seus vínculos políticos e jurídicos com as cidades aliadas e dar continuidade à concepção romana de civitas augescens.

62 O principal interesse dos latini e dos itálicos em lutar pelo reconhecimento da cidadania romana era ligado ao fato dos cidadãos romanos terem sido isentados, a partir do ano de 167 d. C., do pagamento de impostos diretos. Se até aquele determinado momento existia um literal desinteresse da parte do povos anexados pela cidadania romana, com a isenção tributária acontece uma verdadeira reviravolta, que culmina na guerra social. Neste âmbito, é importante também salientar, que com Caio Graco nasce a concepção assistencialista romana, ou seja, o cidadão deve cada vez mais ser assistido pelo Estado. Foi um fator que veio a contribuir à revolta dos latini e dos itálicos.

63 As concessões propostas por Caio Graco foram fundamentadas em uma rogatio apresentada pelo cônsul Marco Fulvio Flacco, no ano 125 a. C., derrubada pela forte oposição da nobilitas romana.

64 LOBRANO, Giovanni. A teoria da respublica (fundada sobre a "sociedade" e não sobre a "pessoa jurídica") no Corpus Juris Civilis de Justiniano (Digesto 1.2-4), Revista Sequência, 30, n. 59, dez. 2009, p. 24. 
É importante salientar, porém, o surgimento a partir deste momento histórico do problema eleitoral originado pela progressiva concessão da cidadania aos itálicos. O reconhecimento deste direito a todas as comunidades da península abria caminho para o direito ao voto. Foram violentos os contrastes relativos a esta temática, culminando na aprovação da lex Cornelia de novorum civium et libertinorum suffragis que, no ano de 87 a. C., restringiu a efetiva participação nas assembleias populares somente aos cives residentes em Roma.

Os efeitos jurídicos das concessões obtidas pelos itálicos com a guerra social foram extremamente significativos e permitiram em 49 a.C. a aprovação da lex Roscia, proposta por Caio Júlio César, e que estendeu a cidadania romana a todos os moradores da Gália Transpadana. A gradual expansão da cidadania, tendo por base vínculos culturais e a fidelidade dos povos conquistados, iniciada durante o final da república, tem seu auge durante o império com a Constitutio Antoniniana em 212 d.C., que concedeu a cidadania romana aos homens livres residentes nos territórios do império. ${ }^{65}$

\section{CONSIDERAÇÕES FINAIS}

A comunhão cultural entre Roma e as cidades do Latio foi sempre latente devido à reconhecida origem de Roma nas cidades latinas, à atribuição da origem de reis romanos e aos cultos em comum. A comunhão cultural existente entre Roma e as demais cidades latinas permitiu a construção de uma comunhão jurídica, na qual se reconhece aos latinos um conjunto de direitos que os diferenciam das pessoas oriundas de outras cidades. O status de latinus diferencia-se substancialmente, portanto, do status de peregrinus. O termo peregrino pode ser comparado ao de estrangeiro, como pessoa não romana com quem não há necessariamente uma comunhão cultural e jurídica.

A concepção de abertura de Roma ao não romano forma-se certamente pela comunhão com a comunidade latina, comunidade da qual Roma se forma e no seio da qual se desenvolve. $O$ paulatino enfraquecimento da distinção entre civis e latinus, ao ponto de ser estendida a cidadania romana a todos os habitantes do Latio, reflete o universalismo romano e consolida a comunhão cultural por meio do ius.

A compreensão da relação entre romanos e latinos reflete-se na expansão de Roma e no aumento da civitas, concebida como potencialmente universal. Essa experiência de ius civitatis denota uma diferente concepção de cidadania em relação àquela proposta pelo modelo do Estadonação, defendida por Mancini e concernente à nacionalidade. ${ }^{66}$

Em termos de expansão da cidadania romana, não em uma ótica especificamente latina, observase ainda na história do Brasil experiência comparável de certa forma a evento de expansão da cidadania romana. Traços da expansão da cidadania presentes na Constitutio Antoniniana, de 212 d.C., podem ser aproximados àquele aplicado pela República dos Estados Unidos do Brasil com o Decreto n. 58 A de 14 de dezembro de 1889 , por meio do qual o governo realizou uma naturalização coletiva, que ficou conhecida como "A Grande Naturalização".67

A visão romana de comunhão cultural com os povos latinos reflete uma possibilidade de concepção da cidadania que, embora se aproxime do atual modelo do "estatuto de igualdade", baseado na reciprocidade, ou da flexibilização da concessão da cidadania aos originários de países de língua portuguesa, abre espaço para algo ainda diferente, concebido mais em uma visão humanística do que nacional.

65 Ulp. dig. 1,5,17. A constituição antoniniana pode ser acessada no endereço http://web.upmf-grenoble. fr/Haiti/Cours/Ak/Constitutiones/Antoniniana_Girard.htm. GROSSO, Enrico. Le Vie della Cittadinanza. Le Grandi Radici. I Modelli Storici di Riferimento. Padova: Cedam, 1997, p. 121.

66 MANCINI, Pasquale Stanislao. Prelezione al corso di diritto pubblico esterno ed internazionale privato, tenuta da P.S. Mancini nella R. Università do Torino, il 22 gennaio 1851. In: JAYME. Erik (a cura di). Della nazionalità come fondamento del diritto delle genti. Torino: Giappichelli, 2000, p. 45.

67 O prazo estabelecido no referido decreto 58-A foi prorrogado pelo Decreto n. 479 até 31 de dezembro de 1890. Esse tipo de "naturalização em virtude de lei" também foi previsto no art. 69 (incisos 4 e 5) da Constituição da República dos Estados Unidos do Brasil (de 24 de fevereiro de 1891). Ver sobre o assunto: ALEXANDRE, Francisco. Naturalizados e outros aspectos da nacionalidade. Rio de Janeiro: A. Coelho Branco Filho, 1956, p. 91 DAL RI, Luciene. A construção da cidadania no Brasil: entre Império e Primeira República. Espaço Jurídico, Joaçaba, v. 11, n. 1, p. 7-36, jan./jun. 2010, p. 18 ss. 
ALEXANDRE, Francisco. Naturalizados e outros aspectos da nacionalidade. Rio de Janeiro: A. Coelho Branco Filho, 1956.

AMIRANTE, Luigi. Una storia giuridica di Roma. Napoli: Jovene, 1991.

ARENDT, Hannah. Entre o passado e o futuro. São Paulo: Perspectiva, 2003.

BACCARI, Maria Pia. Cittadini, popoli e comunione nella nlegislazione dei secoli IV-VI. Torino: Giappichelli, 1996.

BELLINI, Vincenzo. Sulla genesi e la struttura delle leghe nell'Italia arcaica. RIDHA série, VIII, III (1961).

BENVENISTE, Émile. Le vocabulaire des institutions indo-européennes, I. Économie, parenté, société. Paris: Minuit, 1969.

CARLE, Giuseppe. Le origini del diritto romano. Torino: F.lli Bocca, 1888.

CATALANO, Pierangelo. Linee del sistema sovrannazionale romano. Torino: Giappichelli, 1965.

CATAlANO, Pierangelo. Populus Romanus Quirites. Torino: Giappichelli, 1974.

CATALANO, Pierangelo. La divisione del potere in Roma (A proposito di Polibio e Catone). Studi in onore di Giuseppe Grosso VI. Torino: Giappichelli, 1974a.

CATALANO, Pierangelo. Aspetti spaziali del sistema giuridico-religioso romano. Mundus, templum, urbs, ager, Latium, Italia. Aufstieg und Niedergang der Rômischen welt, II, Principat 16.1, 1978.

CATALANO, Pierangelo. Seduta preliminare. Seminari Internazionali di Studi Storici "Da Roma alla Terza Roma" (La nozione di "romano" tra cittadinanza e universalità). Napoli: Ed. Scientifiche Italiane, 1982.

CATALANO, Pierangelo. Alcuni concetti e principi giuridici romani secondo Giorgio La Pira. In: Il ruolo della buona fede oggettiva nell'esperienza giuridica storica e contemporanea. Padova: CEDAM, 2003.

CATALANO, Pierangelo. Promemoria, in XXVII Seminario Internazionale di Studi Storici "Da Roma alla terza Roma". Roma, 2007.

CERAMI, Pietro et CORBINO, Alessandro. Storia del Diritto Romano. Messina: Rubettino, 1996.

COLI, Ugo. Il diritto pubblico degli Umbri e le tavole Eugubine. Milano: Giuffrè, 1958.

COLOGNESI, Luigi Caprogrossi. Lezioni di storia del diritto romano. Monarchia e Repubblica. Napoli: Jovene editore, 2004.

CONSTANT, Benjamin. De la liberté des anciens comparée à celle des modernes. Discours prononcé à I'Athénée royal de Paris, 1819.

COSTA, Emilio. Storia del diritto pubblico romano. Firenze: Barbera, 1906.

CRIFÒ, Giuliano. Cittadinanza (diritto romano). In: Enciclopedia del diritto VII. Milano: Giuffrè, 1960.

CRIFÒ, Giuliano. Civis. La cittadinanza tra antico e moderno. Roma-Bari, 2004.

CRIFÒ, Giuliano. Asilo (diritto di). In: Enciclopedia del diritto III. Milano, 1958.

DAL RI, Luciene. A construção da cidadania no Brasil: entre Império e Primeira República. Espaço Jurídico, Joaçaba, v. 11, n. 1, p. 7-36, jan./jun. 2010.

DE FRANCISCI, Pietro. Primordia Civitatis. Romae: Apollinaris, 1959.

DE MARTINO, Francesco. Storia della costituzione romana. Napoli: Jovene, 1973.

DEVOTO, Giacomo. La città e lo stato degli Umbri. L'Umbria nella storia, nella letteratura, nell'arte. Bologna: Zanichelli, 1954. 
DE VISSCHER, Fernand. La dualité des droits de cité et la "mutatio civitatis". In: Studi de Francisci, I, 1954

ELLUL, Jacques. Histoire des institutions. L'Antiquité. Paris: Quadrige/PUF, 1999.

ERNOUT, Alfred. MEILLET, Antoine. Dictionnaire étymologique de la langue latine. Paris: C. Klincksieck, 1959.

FREZZA, Paolo. L'Età classica della costituzione repubblicana. Labeo, 1, 1955.

FREZZA, Paolo. Ius gentium. RIDA, 2, 1949

GAUDEMET, Jean. Les Institutions de I'Antiquité, 7 ed. Paris: Montchrestien, 2002.

GIERKE, Otto F. v. Das deutsche Genossenschaftsrecht III. Graz: Akademische Druck- und Verlagsanstalt, 1954.

GIOLO, Orsetta e PIFFERI, Michele. Diritto contro, meccanismi giuridici di esclusione dello straniero. Torino: Giappichelli, 2009.

GROSSO, Giuseppe. Lezioni di Storia del diritto romano. Torino: Giappichelli, 1965.

GROSSO, Enrico. Le Vie della Cittadinanza. Le Grandi Radici. I Modelli Storici di Riferimento. Padova: Cedam, 1997

HEGEL, Georg W. F. Lezioni sulla filosofia della storia III. Trad. G. Calogero C. Fatta. Florença: Bompiani, 1963.

HEUSS, Alfred. Die völkerrechtlichen Grundlagen der römischen Aussenpolitik in Republikanischer zeit. Leipzig: Dieterich, 1933.

JHERING, Rudolph. Geist des römischen Rechts. Leipzig: Breitkopf\&Härtel, 1877-1880.

LOBRANO, Giovanni. A teoria da respublica (fundada sobre a "sociedade" e não sobre a "pessoa jurídica") no Corpus Juris Civilis de Justiniano (Digesto 1.2-4). Revista Sequência, 30, n. 59, dez. 2009.

MANCINI, Pasquale Stanislao. Prelezione al corso di diritto pubblico esterno ed internazionale privato, tenuta da P.S. Mancini nella R. Università do Torino, il 22 gennaio 1851. In: JAYME. Erik (a cura di). Della nazionalità come fondamento del diritto delle genti. Torino : Giappichelli, 2000.

MOMMSEN, Theodor. Römische Staatsrecht. Leipzig: Teubner, 1887.

NIEBUHR, M. Barthold Georg. Römische Geschichte. Berlin: Calvary, 1811.

NOCERA, Guglielmo. Il binomio pubblico-privato nella storia del diritto. Napoli: Edizioni Scientifiche Italiane, 1992.

ORESTANO, Riccardo. Il problema delle persone giuridiche in diritto romano. Torino: Giappichelli, 1967.

PARADISI, Bruno. Storia del diritto internazionale nel Medio Evo. Milano: Giuffrè, 1940.

PARADISI, Bruno. Osservazioni sul rapporto storico tra diritto internazionale pubblico e diritto internazionale privato. Studi Senesi, 59, 1945.

ROTONDI, Giovanni. Leges publicae populi romani: elenco cronologico con una introduzione sull'attività legislativa dei comizi romani. Milano: G. Olms, 1962.

SERRAO, Feliciano. Diritto privato economia e società. Napoli: Jovene, 2006.

SERRAO, Feliciano. Classi, partiti e legge nella repubblica romana. Pisa: Pacini, 1975.

SHERWIN WHITE, Adrian Nicholas. The Roman citizenship. Oxford: Clarendon Press, 1939.

TONDO, Salvatore. Profilo di storia costituzionale romana. Milano: Giuffrè, 1981. 